\title{
How to devise a sustainable science for sustainability? A reflexive approach for the present time
}

\author{
Elena Camino \\ Interdisciplinary Research Institute on Sustainability, University of Torino, Italy (www.iris.unito.it)
}

\begin{abstract}
Most people refer to science as a 'special way' to produce neutral and objective knowledge about the natural world, and from such understanding draw guidelines to move towards a more sustainable way to inhabit the planet. But there is an increasing gap between approaches aiming at interpreting, and approaches that transform while studying: such transformations may come out to be irreversibly harmful. Besides, science and technology are even more interconnected, so that 'technoscience' is the prevailing way of investigating nature today, and is driven and powered by huge economic interests. How can neutral knowledge be achieved if research questions are so heavily biased? In order to undertake a sustainable journey we need to ask some questions about the role and the features of science in shaping our future. Who are the 'experts' in sustainability science? What are 'sustainable' values in formulating research questions? How to deal with biophysical and social constraints in a sustainable way?
\end{abstract}

The study of all mythology is the study of its metaphors.[...] Mythology is not an ideology. It is not designed from the brain, but it is experienced through the heart. [1]

\section{From one science to many sciences, from description to interference}

Even if most people keep talking about science in the singular form, the scientific investigation of the natural world has now assumed a multiplicity of forms, means and purposes. We are witnessing a proliferation of disciplines which explore the world through the eyes of ever more specialized experts, from nuclear physicists to evolutionary biochemists. Such gaze became increasingly acute with the narrowing of the research questions, the delimitation of space and time scales, the tools developed and the resources made available. To the point that some scholars underline the 'disunity' of science [2] while others [3] argue for a pluralist attitude towards the theoretical diversity of scientific subfields.

But a far more radical and profound change has occurred in recent decades: the science - from descriptive and interpretative as it was - has become transformative. Not all scientific inquiries show this feature but, when addressing issues of sustainability, this point assumes relevance and is source of concern. The main drivers of the recent, deep changes undergone by natural systems are derived from results achieved by science itself (e.g. the ability to capture nitrogen from the atmosphere), and increasingly from the manipulation of living systems (e.g. from 3 to 9 per cent of the agricultural crops in the world are GMO).

\section{Scientists' appeals}

A Manifesto, signed by more than 520 scientists, draws the attention of policy makers on five global problems to be solved, starting today: 1. climate disruption, 2. extinctions, 3. loss of ecosystem diversity, 4. pollution, 5. human population growth and resource consumption [4]. Such "Scientists' consensus on maintaining humanity's life support systems in the $21^{\text {st }}$ century" sounded the alarm but did not offer uniform and coherent prescriptions about how to cope with such problems.

Exploring the scientific literature on sustainability, we find that, with ever more accurate descriptions of the risky transformations taking place in the global natural systems, a variety of suggestions are provided for citizens and policy makers in order to prevent a global scale shift of the planet. Some Authors [5] suggest to improve earth system governance in order to navigate the Anthropocene, while others [6] opt for a responsible stewartship that entails emulating nature in terms of resource use and waste transformation and recycling. Some [7] find it essential to improve forecasting to minimize biological surprises that would adversely impact humanity. Recently [8] affirm that a global collapse appears likely, and only a dramatic cultural change provides the main hope of averting calamity. [9] believe that humanity has entered a new renaissance period, thanks to the dramatic change from a world view that perceived people and nature as separate actors to one that sees them as interdependent social-ecological systems. The contributions represent what is usually called sustainability science: although with different emphases, they recommend solutions that imply an increase of the collection of quantitative data on complex socio-natural systems meanwhile fostering major changes in lifestyle and social organization of human communities.

\footnotetext{
1 elena.camino@unito.it
} 
Meanwhile another type of approach is rapidly developing; this scientific enterprise, which is lavishly funded by public institutions and private firms, is mainly engaged in the innovation challenge. Humans have demonstrated great creativity in how we use technological, social, and cultural "tools" to solve resource limitations [10], so there is optimism about the adaptive capacity of humanity to overcome seemingly insurmountable constraints. Such positive attitude imbues the imaginaries of techno-scientific innovation, based on wonder, power, control and urgency [11]. Innovation is considered as the decisive step along a path-dependent transition from normal, curiosity-oriented science creating common knowledge, to big, industrial, goaloriented technoscience producing corporate know-how [12] ever more committed to solve the current socio-environmental problems.

\section{How to navigate the variety of offerings?}

Most scientists explicitly affirm that science has the authority and the duty to guide policies, by promoting the public debate, qualified and independent, based on data, measurement and scientific method ${ }^{2}$. So decision-makers and citizens turn to science to get hints about the courses of action to be made in order to guide human communities towards a more sustainable world. But there is no longer one science! The appeal to rely on scientific knowledge to settle the increasingly frequent social and environmental global problems does not discriminate among the variety of 'sciences' to which resort. And different types of science offer different solutions.

Different, and increasingly divergent, are the visions of the world that elicit the research questions, suggest ways to look for answers and determine the goals to be pursued. Every scientific approach derives from a 'frame' which shapes the relationship between 'subject 'inquiring and' 'object' explored. Humanity can be considered as 'external' to the planet, and succeed in dominate and control it? Through synthetic biology researchers will be able to unravel the secrets of life and to direct it towards more 'useful', 'efficient' shapes and functions, to suit growing human needs? For some people these are legitimate questions and stimulating research agendas. For others such ideas are nonsense: according to their view, it should be acknowledged that humanity, along with all the other components of the biosphere, is totally dependent on natural systems, and subject to evolutionary transformations that ceaselessly shape and mold all levels of life (from molecules to biomes) without any chance to take control over upcoming unpredictable events.

\section{We are embedded in frames}

The word 'frame' that I mentioned before can be defined as a structured configuration of semantic roles that constitutes cultural or world knowledge. Worldviews are expressed collectively through cultural and artistic events, political decisions, laws, educational projects, and are transmitted mainly through the language - the natural language and the images and gestures that we use to communicate. Language is a way of being in the world, an instrument which enables us to conceive, organize and represent a view of reality and act according to that view. It is a system made of signifiers (words, symbols, images, etc.), interconnected elements that create links to exploit the mind's potential for the construction of signifieds (meanings) [13].

So language conveys not only information, but ideas and visions. It contains elements of ambiguity and evolves continuously. The awareness of the power and limits of language may promote the development of reflective thinking, able to unveil implicit ideas and uncover underlying imaginaries. Such an attitude may help to make one's own choices and to bear the responsibility of one's adhesion and /or contribution to one of the frames - also scientific frames - that are driving our society, or to the creation of new frames.

\section{Metaphors shape science... and society}

We live in an elegant universe. The cosmos is like a string symphony. Genes are selfish. Zombie Endocrine Disruptors... Scientists need metaphors to make sense of what they explore, to share their interpretations within their own laboratories, and to communicate the outcomes of their research to the public. Besides, as the search fields move away from the scale of our perceptions (as the search in the very small, or the far away, or the super fast), it is necessary to invent metaphors to describe, explain and make sense of aspects of reality to which we are totally alien, and that we seek to seize using tools that are interposed with more and more complex modes between subject and object. Moreover, scientific research and communication are increasingly making use of images - that is iconic metaphors - that help building a mental world that unavoidably retains the same signs of the world we know.

From where scientists draw the inspiration to build the metaphors with which they describe new discoveries and interpret aspects of the natural world ever more distant from human perception? To ask this question entails bringing to light the view of the world, the mental 'frame' that guides researchers in their investigations.

While scientists engage in exploring ever more wide and far landscapes of the natural world, and multiply their approaches and tools, it turns out that the scientific enterprise is collectively extracting from nature innumerable facts from which different pictures of reality can be assembled, depending in part on the social, institutional, or political context within which those doing the assembling are operating [14]; that is, depending on the mental patterns and metaphors that translate them into the language. In a

\footnotetext{
${ }^{2}$ Letter sent to the President of the Italian Republic, october 2013. First signatories Tartaglia, Mercalli and Ulgiati.
} 
more general sense our knowledge is implicitly and unavoidably influenced by the values that shape research questions [15] and by the constraints of language [16].

\section{Medical metaphors}

Scientists who report the ongoing transformations of planetary systems refer often to the metaphor of the patient - doctor relationship. According to one interpretation, humans are the patients: pride and arrogance of the consumeristic and aggressive modern society, driven by the greed of a powerful minority, is a symptom of pathological and self-destructive behavior, that has to be countered by fostering awareness of the human dependence on natural systems and by developing attitudes of humility and resilience. On the other side, the scientific enterprise has effectively achieved an enormous potential of action on our planet [17]. Where the prevailing vision is that of Gaia' body being ill, the metaphor includes the justification for intentional manipulation of the planet. Some key sectors of modern technoscience explicitly advocate this perspective, and the related scientific production is rich in metaphors that not only refer to the idea of scholars being experts, able to deal with the troubles of the planet thanks to their superior knowledge, but describe the planet as a passive element on which to act. Geoengineering and synthetic biology are two examples of this 'frame of mind', that features the modern technosciences, GRAIN (Genomics, Robotics, Artificial Intelligence and Nanotechnology [18].

The metaphors used by scholars and experts of these fields give us cues of the underlying worldviews that shape mental frames and suggest research questions and social goals.

\section{Synthetic biology}

According to the Royal Academy of Engineering [19] modern synthetic biology "aims to design and engineer biologically based parts, novel devices and systems as well as redesigning existing, natural biological systems". A central aim of synthetic biology is to increase the ease and efficiency with which biological systems can be designed and constructed.. Over the past decade the synthetic biology community has built a large collection of biological parts and devices [20]. While the Human Genome Project promised to cure all human ills, the focus of synthetic biology is more on curing the ills of the planet, by promising applications such as the environmentally friendly production of chemicals, bioremediation, production of energy, production of smart materials and biomaterials and counter-terrorism.

Older genetic and genomic projects, especially the human genome project, focused on gaining new insights through mapping, deciphering and reading: now the focus is on turning natural processes and the process of life itself into construction processes designed and controlled by humans [21]. Whereas in the past the "building blocks" were, in a sense, made and put together by "nature," they are now designed and assembled (and hopefully controlled) by humans.

\section{Geoengineering}

'Living with Environmental Change' is a partnership of 22 major UK public sector funders and users of environmental research, including research councils and central government departments ${ }^{3}$. In a Report of this Group, geoengineering is defined as "the deliberate, large-scale manipulation of the planetary environment to counteract anthropogenic climate change" The Authors claim that their report - asking for more research to be implemented - contributes impartial scientific analysis of key knowledge gaps to aid future planning of such research, thereby informing a rational debate on this issue ${ }^{4}$.

Also in this research field, the analysis of language may contribute to develop some awareness on the world views that nurture research questions and experimental protocols.. In a research on newspapers and reviews addressed to the general public [22] reflect upon the social and ethical implications of the metaphorical framing of geoengineering, and highlight several metaphors: the planet is a machine, the planet is a body, the planet is a patient. According to some Authors, geoengineering is applying medical treatment to the planet. We as humanity are addicted to burning carbon fossil fuels. To deal with this addiction we can either spend a lot of time and money on rehabilitation or, when things are too bad, go for replacing the addictive substance by a replacement.

\section{The irruption of values}

\section{Set in military landscapes...}

Technoscience is confident in humanity's capacity to control natural systems, appeals to the virtues of traditional science ('the scientific method' and the 'experimental evidence') and proposes to find silver bullets ${ }^{5}$ to solve the problems, drawing openly upon a military language. Let us turn once again to the language, by exploring another research field heavily dependent on metaphors: the 'nanoworld'. Nanoscience and nanotechnology are disseminating the planet with a huge amount of new 'objects'

\footnotetext{
${ }^{3} \mathrm{http}: / /$ www.lwec.org.uk/

${ }^{4}$ The possible recourse to Geoengineering was mentioned by the Working Group I Contribution to the IPCC Fifth Assessment Report Climate Change 2013: Approved Summary for Policymakers, IPCC WGI AR5 SPM-1 27 September 2013

${ }^{5}$ Silver bullet, used as a metaphor, refers to any straightforward solution perceived to have extreme effectiveness
} 
with sizes of the same range of cellular components. The use of man-made nanoparticles has spread into almost every area of our lives: food, clothing, medicine, toothpaste, sunscreen, and thousands of other products.

A metaphoric frame that has been especially used as the setting of action of nanoparticles in the field of medical care is characterised by an arm race to find cures that can fight diseases. Smart bombs that could smash cancer, nano-weapon hope for cancer patients, stealth tactics to hit cancer cells hard effectively illustrate the close connection with the ideas that meanwhile bloom in society.

\section{... or participating in the Gaia's breath?}

A paper published recently offers a new metaphor: according to [23] we are witnessing a new phenomenon, a hyperventilating biosphere! The planet appears to be a living subject, who is reacting creatively to the global changes that are taking place by going into hyperdrive. Is the biosphere enjoying the global warming? Or she gasps because of changing climate? Many hypotheses, but no answers are currently available. The creative nature of our planet is underlined by another paper [24]: a mounting evidence indicates that tropical cyclones are not passive players in Earth' climate systems, rather they actively contribute to the dynamics of ocean and atmosphere. Other clues that reveal the active, creative and unpredictable temper of the biosphere come from research on evolutionary processes: speciation by hybridization is likely to be a signature of the Anthropocene [25]. Besides, who knows what is going on simultaneously at the other levels, as any macroevolutionary question must be considered from various perspectives, including mutational processes within the genome, mechanisms of developmental regulation, the genetics of populations etc? [26].

\section{From sciences to values}

Quantitative research performed by experts of sustainability science on a huge number of parameters - from the energy fluxes to the cycles of nitrogen to the number of extinct species - is outlining an ever more accurate picture of the present global turmoil, impelling policy makers and civil society to seek for solutions ... coming from science again! But to which of the several sciences that are present on the market, which run in a highly competitive race to get more and more private and public funds and promise to give practical answers? Shall we turn to the reassuring image of innovation science, that offers short term, innovative answers to urgent problems, removing any mention to the increasing zones of ignorance? Or shall we prefer practicing a resilience thinking, and try to investigate ever more well scientifically tested strategies for adapting to the ongoing changes?

Or, with a surge of creativity, may we begin to develop a new way of knowing the natural systems and of experiencing inside them, by practising a "sustainable science"? Such science might be developed by listening at a plurality of legitimate perspectives and views (of experts and lay people as well), rooted on the acknowledgment of biophysical [27] and social [28] boundaries, and explicitly committed to meeting the needs of equity and justice for all Earthlings [29].

\section{References}

[1] J. Campbell, Le distese interiori del cosmo. TEA (2003)

[2] J. Dupré, The Disorder of Things. Metaphysical foundations of the disunity of science, Harvard University Press (1993)

[3] S. Kellert with Helen Longino, and C. Kenneth Waters (eds.), Scientific Pluralism (Minnesota Studies in the Philosophy of Science, Vol. XIX), Minneapolis: University of Minnesota Press (2006)

[4]URL: http://opr.ca.gov/docs/Exec_Sum_Consensus_Statement_for_Web_5-21-13.pdf.

[5] F. Biermann et al. Science 335,1306-7 (2012)

[6] W. Steffen et al. Ambio 40 (7), 739-761 (2011)

[7] A. D. Barnosky et al. Nature 486, 52-58 (2012)

[8] P. R. Ehrlich, A. H. Ehrlich, Proc. R. Soc. B 280, 20122845 (2013)

[9] C. Folke and L. Gunderson Ecology and Society 17(4), 55 (2012)

[10] J.H. Matthews, F. Boltz, PLoS Biol 10 (2012).

URL:http://www.plosbiology.org/article/info\%3Adoi\%2F10.1371\%2Fjournal.pbio.1001344

[11] A . Benessia, S. Funtowicz. in L'innovazione tra utopia e storia, 55-121, Codice (2013).

[12] R.Strand, K. Rommetveit, S. Funtowicz, Deliverable 5.4.2, Seventh framework Programme, Capacities Work Programme: Part 5 - Science in Society (2011).

[13] M.A.K. Halliday, Language as Social Semiotic: The Social Interpretation of Language and Meaning, London, Edward Arnold (1978)

[14] D. Sarewitz, Environmental science and policy 7, 385-403 (2004)

[15] J. R. Ravetz, Futures, 43, 142-148 (2011)

[16] L. Wittgenstein, Tractatus Logico-Philosphicus London, Routledge \& Kegan Paul (1974)

[17] B. Latour, A Plea for Earthly Sciences, keynote lecture for the annual meeting of the British Sociological Association, East London (2007)

[18] J. Ravetz, The No-Nonsense Guide to Science. Between the Lines (2005)

[19] Royal Academy of Engineering, Synthetic biology: scope, applications and implications. London: The Royal Academy of

Engineering (2009). [online] URL: http://www.raeng.org.uk/news/releases/shownews.htm?NewsID=491.

[20] P.E. Purnick, R. Weiss, Nat Rev Mol Cell Biol 10, 410-422 (2009)

[21] I. Hellsten \& B. Nerlich, New Genetics and Society, 30 (4), 375-397 (2011) 
[22] B. Nerlich \& R. Jaspal, Metaphor and Symbol, 27 (2), 131-147 (2012)

[23] I. Fung, Science 341, 1075-1076 (2013)

[24] R.L. Sriver, PNAS, 110 (38), 15173-15174 (2013).

[25] C. D. Thomas, Nature 502, 7 (2013)

[26] T.R. Gregory, Molecules and macroevolution. A Gouldian view of the genome. In Stephen Gould: the scientific legacy, Springer, 53 (2013)

[27] J. Rockström et al. Nature 461, 472-475 (2009)

[28] K. Rawort, URL: http://blogs.oxfam.org/en/blog/12-02-13-can-we-live-inside-doughnut-why-world-needs-planetary-andsocial-boundaries

[29] B. Latour, Waiting for Gaia. Composing the common world through arts and politics, A lecture at the French Institute, London (2011) 